\title{
Total Hip Arthroplasty after McMurray's Osteotomy - A Case Report and Review of Literature
}

\author{
Sangeet Gawhale ${ }^{1}$, Sagar Bansal ${ }^{1}$, Amit Yadav ${ }^{1}$, Shaswat Mishra ${ }^{1}$, K S Akshay ${ }^{1}$, Angad Chikodi ${ }^{1}$ \\ Learning Point of the Article: \\ S-ROM modular total hip arthroplasty provides a viable and effective way for management op cases of previous McMurray's osteotomy.
}

\section{Abstract}

Introduction: Total hip arthroplasty after McMurray's osteotomy increases the operative difficulties and decreases the chances of better outcome. With the advent of modular femoral stems, minute changes can be done to individual joints, which allow intraoperative flexibility and better post-operative outcome. Thus, it should be considered as an option for complicated cases.

Case Report: We report a case of a 35-year-old female with chief complain of pain in the left hip while walking for the past 2 years. The patient also had difficulty in squatting and sitting cross legged. History of fracture in the left hip at 4 years of age for which McMurray's osteotomy was done. The patient was operated with total hip arthroplasty using modular Sivash range of motion (S-ROM) stem.

Conclusion: Modular S-ROM total hip arthroplasty is a good option for treatment in cases with previous osteotomy in femur.

Keywords: McMurray's osteotomy, total hip arthroplasty, Sivash range of motion.

\section{Introduction}

McMurray's osteotomy is frequently used for the management of malunited femoral neck fractures or those with nonunion and delayed union. Mostly, it is done to buy time before a definitive replacement procedure is done, but this delay in definitive procedure leads to enhanced technical difficulties during the replacement procedure and increased complication rate. With better understanding of hip biomechanics and innovative implants, total hip arthroplasty can now be done for wider range of indications including failed previous operation. Modular stems reinstate the natural biomechanics of the hip joint as it permits fine tuning of the joint by allowing considerable intraoperative flexibility. Large number of modular stem types has been introduced because of their versatility $[1,2,3]$. Nowadays, for both primary and revision surgeries, modular stems are commonly used. Here, we report the case of total hip arthroplasty after McMurray's osteotomy using modular stem.

\section{Case Report}

A 35-year-old female presented with complaints of pain in the left hip while walking for the past 12 years and difficulty in squatting/sitting cross legged. History of fracture in left hip at 4 years of age for which McMurray osteotomy was done. On examination, she had tenderness at the left hip, trochanteric thickening, widening, and proximal migration. There was shortening of $2 \mathrm{~cm}$ accompanied by Trendelenburg gait. Hip joint rotation was restricted with flexion possible up to $90^{\circ}$, adduction till $10^{\circ}$, and $40^{\circ}$ of abduction.

Radiograph anteroposterior and lateral view of femur, and magnetic resonance imaging were suggestive of loss of joint space with flattened and distorted head (Fig. 1 and 2), there was medialization of femur shaft along with shortened neck. Malunion at intertrochanteric region was accompanied by distorted and sclerotic acetabulum. Patients blood parameters were within normal range.

The patient was planned for modular Sivash range of motion (S-

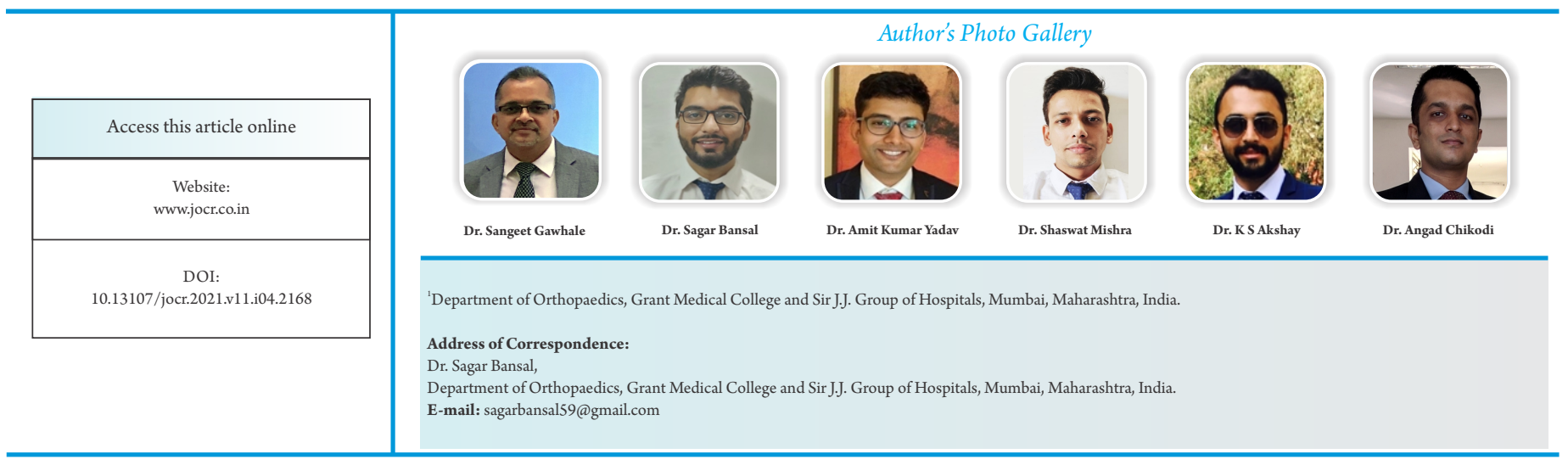

Journal of Orthopaedic Case Reports | pISSN 2250-0685 | eISSN 2321-3817 | Available on www.jocr.co.in | doi:10.13107/jocr.2021.v11.i04.2168 This is an Open Access article distributed under the terms of the Creative Commons Attribution Non-Commercial License (http://creativecommons.org/licenses/by-nc/3.0) which permits unrestricted non-commercial use, distribution, and reproduction in any medium, provided the original work is properly cited. 


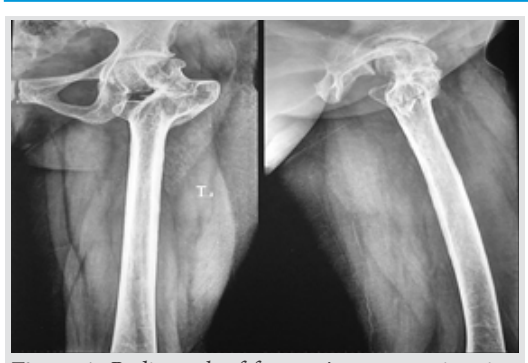

Figure 1: Radiograph of femur: Anteroposterior view andlateral view.

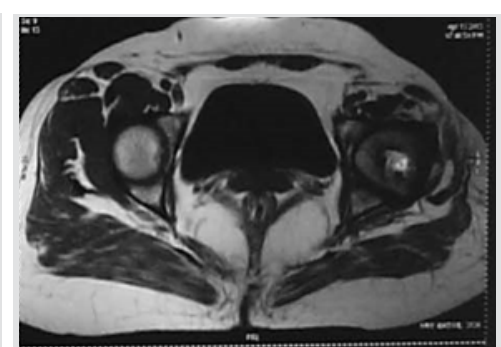

Figure 2: Magnetic resonance imaging axial section of proximal femur

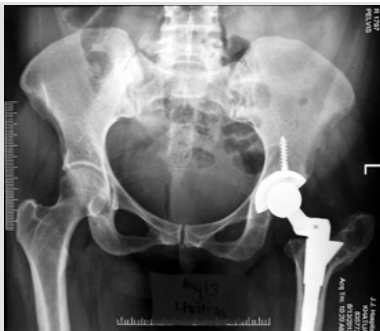

Figure 3: Post-operative radiograph of pelvis with both hips view.

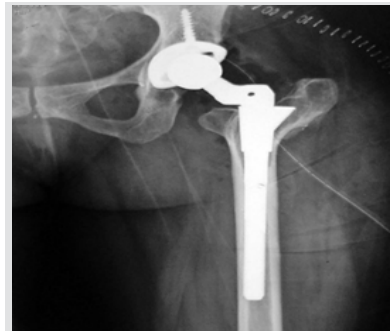

Figure 4: Post-operative radiograph of femur anteroposteriorview.
ROM) total hip arthroplasty (Fig. 3 and 4). The patient was started with bed side mobilization and walking with support of walker from post-operative day 3 . The patient had no pain and was able to walk freely without any support from post-operative day 7. At subsequent follow-up at 3 months, 6 months, and 2 years, the patient had no complaints.

\section{Discussion}

Difficulties faced during a total hip arthroplasty after a previous osteotomy are many and among those the displacement at the osteotomy site is the most significant one. At the osteotomy site, medullary canal is obscured and distorted due to presence of remodeled bone, due to which reaming and prosthesis insertion becomes extremely difficult. Medial bone stock is insufficient because of medialization of the distal fragment. Soballe et al. reported the association between the outcomes of total hip arthroplasty with the amount of displacement of the osteotomy [4]. Thus, while performing McMurray's osteotomy excessive medialization of the shaft should be avoided so that the intraoperative problems faced during definite replacement procedure are significantly reduced. Metaphyseal or diaphyseal abnormalities lead to a mismatch between metaphysis and diaphysis. These problems are not normally seen during routine total hip replacement. Spiral femoral fracture and difficulty in localizing the femoral canal are likely intraoperative problems which may occur. Therefore, identifying the anatomical changes preoperatively and intraoperatively is very important. Here, we will be explaining surgical steps and techniques which can avoid these problems.

Uncemented metal-on-metal articulation hip implant was developed by Sivash in 1956 [5, 6]. Soon, he modified his original implant by applying a proximal modular sleeve. This modification secured maximal contact between the bone and the implant. Soon, an SRN implant was developed by adding porous coating to the proximal sleeve and eight flutes to the distal stem. After some minor changes, it was named as "SROM" in 1982 and has been in use since then. Previous hip surgery distorts the anatomy of proximal femur leading to a wide variety of intraoperative challenges. These can be overcome with the use of S-ROM as it prepares proximal and distal portion of femur independently and creates less hoop stress. By recreating femoral anteversion and milling through cortical bone chances of periprosthetic fractures reduces to a large extent.

Compact fixation between the proximal metaphysis and the modular sleeve provides remarkable proximal stability which is independent of proximal femoral geometry. Bone deficiency is accommodated by longer stems. The presence of fluted long stem provides considerable distal rotational stability. Proximal sleeve allows bone in growth, which provides better initial flexibility and stability. A surgeon can go for suitable sleeve by choosing from various height and width options. Apart from this, numerous stem options with variable neck styles allow the surgeons to adjust medial and vertical offsets. Stem's modularity and rotational freedom made complex revision surgeries relatively easier $[7,8]$. Since, sleeve cements to proximal fragment and stem skewers the same, this aids in providing rotational stability distally and hence S-ROM can be used in complex allograft reconstructions of severe bone deficiency [ 9 , 10].

Thus, a surgeon can make necessary changes in the biomechanics of the femur without worrying about the stability of the implant and hence can overcome the difficulties which are associated with a revision surgery. Complications pertinent to the modular interface raised few doubts during the initial period but ample study and experiment asserted only slight fretting in addition to wear particle production and even at worst case loading situations, the modular junctions were stable $[11,12,13,14,15]$. Other apprehensions related with S-ROM stems are metallosis and fretting corrosions but these are very rare.

The S-ROM prosthesis has been very successful over the years and has proven itself in long-term results both in primary and revision surgeries $[2,16,17,18,19,20]$. Thus, patients operated with S-ROM modular total hip arthroplasty in a previous case of McMurray's osteotomy have considerable reduction in pain, with better hip mobility, and walking ability.

Hence, for such challenging total hip reconstruction, S-ROM modular total hip arthroplasty is recommended. 


\section{Conclusion}

Total hip arthroplasty after McMurray's osteotomy is a difficult procedure with lots of intraoperative complications. Such case when treated with S-ROM modular total hip arthroplasty shows excellent outcome as it offers the advantage of modulation of hip system intraoperatively.

\section{Clinical Message}

Total hip arthroplasty after McMurray's osteotomy can be effectively treated by S-ROM modular total hip arthroplasty.

\section{References}

1. McTighe T, Keppler L, Tkach T. Cementless Modular Stems Chagrin Falls: Joint Implant Surgery and Research Foundation; 2002.

2. Spitzer AI. The S-ROM cementless femoral stem: History and literature review. Orthopedics 2005;28 Supp19:s111724.

3. Krishnan H, Krishnan SP, Blunn G, Skinner JA, Hart AJ. Modular neck femoral stems. Bone Joint J 2013;95B:1011-21.

4. Soballe K, Kolding KL, Kofod S, Severinsen B, Kristensen SS. Total hip replacement after medial displacement osteotomy of the proximal part of the femur. J Bone Joint Surg Am 198;71:642-7.

5. Sivash KM. The development of a total metal prosthesis for the hip joint from a partial joint replacement. Reconstr Surg Traumatol 1969;11:53-62.

6. Salvi AE, Hacking SA. The innovative Sivash artificial total hip joint. UPOJ 2010;20:151-3.

7. Cameron HU. The two to six year results with a proximally modular noncemented total hip replacement used in hip revisions. Clin Orthop 1994; 198:47-53.

8. Chandler HP, Ayres DK, Tan RC, Anderson LC, Varma AK. Revision total hip replacement using the S-ROM femoral component. Clin Orthop 1995;319:130-40.

9. Chandler H, Clark J, Murphy S, McCarthy J, Penenberg B, Danylchuk K, et al. Reconstruction of major segmental loss of the proximal femur in revision total hip arthroplasty. Clin Orthop 1994;298:67-74.

10. Chandler HP. Use of allografts and prostheses in the reconstruction of failed total hip replacements. Orthopedics 1992;15:1207-18.

11. Bobyn J, Dujovne A, Krygier J, Young DL. Surface analysis of the taper junctions of retrieved and in vitro tested modular hip prostheses. In: Morrey B, editor. Biological, Material and Mechanical Considerations of Joint Replacement. New York: Raven Press Ltd.; 1993.

12. Bobyn JD, Tanzer M, Krygier JJ, Dujoyne AR, Brooks CE. Concerns with modularity in total hip arthroplasty. Clin Orthop 1994;298:27-36.

13. Krygier JJ, Bobyn JD, Dujovne AR, Krygier JJ, Young DL. Strength, stability and wear analysis of titanium femoral hip prostheses tested in fatigue. In: Presented at: Transactions of the 4th World Biomaterials Congress, Berlin, Germany; 1992.

14. Krygier JJ, Dujovne AR, Bobyn JD. Fatigue behavior of titanium femoral hip prosthesis with proximal sleeve-stem modularity.J Appl Biomater 1994;5:195-201.

15. Postak PD, Polando G, Pugh JW, Greenwald AS. A New Method of Fatigue Testing for Proximally Supported Femoral Stems, Trans AAOS; 1990.p. 320.

16. Keppler L, Cameron HU, McTighe T. The role of modularity in primary THA: Is there one? In: Annual Meeting of the American Academy of Orthopaedic Surgeons, 22-26 March 2006, Chicago. Rosemont: AAOS; 2006.

17. Mattingly DA. The S-ROM modular stem for femoral deformities. Orthopedics 2005;28 Suppl 9:s1059-62.

18. Buly R. The S-ROM stem: Versatility of stem/sleeve combinations and head options. Orthopedics 2005;28 Suppl 9:s1025-32.

19. Kennon RE, Keggi JM, Wetmore RS, Zatorski LE, Huo MH, Keggi KJ. Total hip arthroplasty through a minimally invasive anterior surgical approach. J Bone Joint Surg Am 2003;85-A Suppl4:39-48.

20. Kennon R, Keggi J, Zatorski LE, Keggi KJ. Anterior approach for total hip arthroplasty: Beyond the minimally invasive technique. J Bone Joint Surg Am 2004;86-A Suppl 2:91-7.

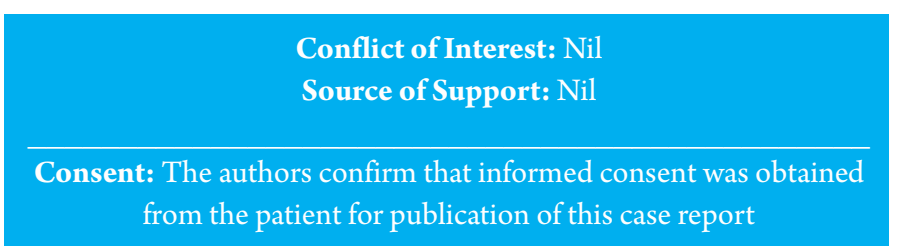

How to Cite this Article

Gawhale S, Bansal S, Yadav AK, Mishra S, Akshay KS, Chikodi A. Total Hip Arthroplasty After McMurray's Osteotomy - A Case Report and Review of Literature. Journal of Orthopaedic Case Reports 2021 April;11(4): 97-99.

Journal of Orthopaedic Case Reports | Volume 11 | Issue 4 | April 2021 | Page 97-99 